Endovascular therapy remains associated with better in-hospital outcomes, including the younger age population with ruptured or unruptured aneurysms.

Disclosures H. Saber: None. M. Jafari: None. A. Desai: None. N. Kaneko: None. G. Colby: 2; C; Medtronic, Stryker, MicroVention. V. Szeder: None. R. Jahan: 2; C; Medtronic. G. Duckwiler: 2; C; Medtronic. S. Tateshima: 2; C; Medtronic, Stryker, Cerenovus.

\section{P-051 TREATMENT OF ACUTELY RUPTURED INTRACRANIAL ANEURYSMS WITH WOVEN ENDOBRIDGE DEVICE: A SYSTEMATIC REVIEW}

${ }^{1} \mathrm{~A}$ Monteiro*, ${ }^{2} \mathrm{~A}$ Lazar, ${ }^{1} \mathrm{M}$ Waqas, ${ }^{1} \mathrm{H}$ Rai, ${ }^{1} \mathrm{~A}$ Baig, ${ }^{1} \mathrm{R}$ Dossani, ${ }^{1} \mathrm{~F}$ Almayman, IJ Cappuzzo, 'I Davies, ${ }^{1} \mathrm{~K}$ Snyder, ${ }^{1} \mathrm{E}$ Levy, ${ }^{1} \mathrm{~A}$ Siddiqui. ${ }^{1}$ Neurosurgery, University at Buffalo Neurosurgery, Buffalo, NY; ${ }^{2}$ Neurosurgery, Gates Vascular Institute at Kaleida Health, Buffalo, NY

\subsection{6/neurintsurg-2021-SNIS.87}

Introduction The Woven Endobridge (WEB) device is a barrelshaped nitinol mesh deployed within the aneurysmal sac. The absence of metallic mesh in the vessel lumen obviates the need for potent antiplatelet therapy, which makes this devices interesting for acutely ruptured aneurysms not amenable to clipping or coiling.

Methods We performed a comprehensive systematic search of Pubmed, MEDLINE and EMBASE databases following the Preferred Reporting Items for Systematic Reviews and MetaAnalyses (PRISMA) guidelines. Keywords combined with Boolean operators to increase search sensitivity and specificity ('woven endobridge device' AND 'ruptured') were used.

Results Five studies were included, totalizing 276 ruptured aneurysms. Overall, $222(80.4 \%)$ were wide-neck and 236 $(85.5 \%)$ were located in the anterior circulation. Grade of SAH based on Hunt and Hess scale was reported in four studies with $64(25.7 \%)$ of patients presenting with a poor grade (Hunt and Hess 4-5). Intraoperative and post-operative complications occurred in 7.2\% (95\% CI, 3.8-13.4) and $4.3 \%$ (95\% CI, 1.9-9.2) respectively. The rate of rebleeding after treatment was $0 \%$. The rates of adequate occlusion and retreatment at last follow-up were $86.5 \%$ (95\% CI, 75.6-93) and $5.9 \%$ (95\% CI, 3.2-10.6), respectively. The rate of favorable outcome was $71 \%$ (95\% CI, 64-77) and mortality was $19.4 \%$ (95\% CI, 14.3-25.7). The United-States multicenter study reported use of intraoperative single-antiplatelet therapy (SAPT) in $13.1 \%$ and dual-antiplatelet therapy (DAPT) in $2.2 \%$, while $18.7 \%$ were discharged under DAPT. The remaining 4 European studies reported no use of antiplatelets during the procedure unless stenting was needed. Two studies reported no use of antiplatelet regimen during follow-up, while 2 studies reported use of SAPT for 4-6 weeks.

Conclusions Treatment of acutely ruptured aneurysms with WEB device results in high rates of adequate occlusion, with low perioperative complications, no rebleeding and low recurrence. This device is promising for wide-necked ruptured aneurysms that are not amenable to clipping or coiling, considering its lower need for antiplatelet regimen either during procedure or follow-up.

Disclosures A. Monteiro: None. A. Lazar: None. M. Waqas: None. H. Rai: None. A. Baig: None. R. Dossani: None. F. Almayman: None. J. Cappuzzo: None. J. Davies: 1; C; National Center for Advancing Translational Sciences of the National Institutes of Health under award number
KL2TR001413 to the University at Buffalo. K. Snyder: 2; C; Canon Medical Systems Corporation, Penumbra Inc., Medtronic, and Jacobs Institute. E. Levy: 2; C; Claret Medical, GLG Consulting, Guidepoint Global, Imperative Care, Medtronic, Rebound, StimMed;. 4; C; NeXtGen Biologics, RAPID Medical, Claret Medical, Cognition Medical, Imperative Care (formerly the Stroke Project), Rebound Therapeutics, StimMed, Three Rivers Medical;. A. Siddiqui: 2; C; Amnis Therapeutics, Boston Scientific, Canon Medical Systems USA Inc., Cerebrotech Medical Systems Inc., Cerenovus, Corindus Inc., Endostream Medical Ltd., Imperative Care, Inc. Integra LifeSciences C. 4; C; Adona Medical, Inc, Amnis Therapeutics, (Purchased by Boston Scientific October 2017), Blink TBI Inc., Buffalo Technology Partners Inc., Cerebrotech Medical Systems, Inc., Cognition Medical, Endostrea.

\section{P-052 A NOVEL EX-VIVO MODEL TO SIMULATE DELAYED ANEURYSM RUPTURE AFTER FLOW-DIVERTER TREATMENT}

${ }^{1} \mathrm{H}$ Sodawalla*, ${ }^{1} \mathrm{~W}$ Merritt, ${ }^{2} \mathrm{G}$ Uyeda, ${ }^{3} \mathrm{~T}$ Becker. ${ }^{1}$ Bioengineering Program (Department of Mechanical Engineering), Northern Arizona University, Flagstaff, $A Z ;{ }^{2}$ Department of Applied Physics and Materials Science, Northern Arizona University, Flagstaff, $A Z ;{ }^{3}$ Bioengineering Program (Department of Mechanical Engineering), Northern Arizona University, Flagstaff, AZ

\subsection{6/neurintsurg-2021-SNIS.88}

Introduction/Purpose It is estimated that 3-6 million Americans harbor a brain aneurysm and are at risk for hemorrhagic stroke (rupture). Flow-diverter placement in the blood vessel (fine mesh stent placement) across giant intracranial aneurysms (GIAs) is the standard of care. However, up to $20 \%$ of these aneurysms still experience delayed aneurysm rupture (DAR). Intra-aneurysmal thrombus formed after a flow-diversion treatment releases matrix metalloproteinase (MMPs) that can degrade the extracellular matrix of an aneurysmal wall and cause delayed rupture. Current in vivo aneurysm models (i.e., swine/canine vein pouch-to-artery anastomosis models and rabbit-elastase models) result in relatively stable aneurysms and do not model giant aneurysms, nor do they simulate the tissue degradation preceding DAR. This study evaluated the mechanobiological properties of mouse arterial vessel wall digestion by MMP- $1 / 2 / 9$ proteins with the aim of creating a novel exvivo DAR model.

Materials and Methods Abdominal aorta tissue was harvested from homozygous inbred female mice (The Jackson Laboratory, Bar Harbor, Maine) within 3 hours of sacrifice and flushed with phosphate buffered saline. The tissue samples were then divided into 5 groups ( $\mathrm{n}=4$ each for group): porcine pancreatic elastase (PPE) treated group, MMP-1 group, MMP-2 group, MMP-9 group, and a cocktail group (3 MMPs in equal quantities). Each group includes three trials per group - control trial, low dose trial $(0.2 \mathrm{ug} / \mathrm{ml})$ and high dose trial (2 $\mathrm{ug} / \mathrm{ml})$. The three trial groups were tested for macroscopic mechanical properties, using non-destructive testing protocols for shear modulus, compression modulus and tensile modulus, with NAU's HR-2 rheometer (TA Instruments, New Castle, DE). Testing was conducted before (control) and after incubation for 2 hours at $37^{\circ} \mathrm{C}$. For microscopic mechanical analysis, prior to tissue fixation, the tissue samples were visualized with confocal microscopy to determine changes in its arterial structure and atomic force microscopy (AFM) to quantify enzyme tissue digestion. 